\title{
RELATION BETWEEN GLOBAL ENVIRONMENTAL ISSUES AND SURFACE WATER QUALITY
}

\author{
Ákos Rédey, Ferenc Husvéth, Zsófia Kovács, Anett Utasi and Endre \\ Domokos \\ University of Pannonia,10. Egyetem Str., 8200, Veszprém, Hungary
}

\begin{abstract}
Water is one of the most vital natural resources for all life on Earth. Water is strategic important, limited available, vulnerable and economically crucial resource. Water is essential for maintaining human health, precondition of economical development and resource of the natural beauty. The most challenging goal in the 21st century is how to obtain clean water and its alarming signs are already critical. Estimates suggest that nearly 1,2 billion people lack safe drinking water and at least 500 million people suffer from water scarcity. Climate changes are able to speed up this process (World Water Day, 2007). According to studies the range of draught areas are increasing rapidly furthermore according to Climate Report of UN (2007) the water resources came from melting glacier is decreasing continuously that concern one sixth of the population (Faragó, 2007). Until now glaciers have provided clean and good quality water but the demand for water is increasing in parallel with the rapidly expanding population.
\end{abstract}

\section{Introduction}

Significant part (97\%) of water supply of Earth exists in sea and ocean and because of their high salt content are not adequate drinking, industrial activities and agricultural goals (Fig.1).

The remaining $2-3 \%$ is freshwater that are mainly ice and only 0,3 per cent of Earth's water supply is adequate for drinking including surface water, streams, lakes (USGS). In the view point of mankind the most critical warning is the disappearance of polar snow pack due to its melting.

Water consumption has been increasing all over the world and the distribution of water supply is spatial and temporal unequal. Global worry in connection with water is closely linked with growing population and decreasing of water supply for one person. 
Ákos Rédey et al.

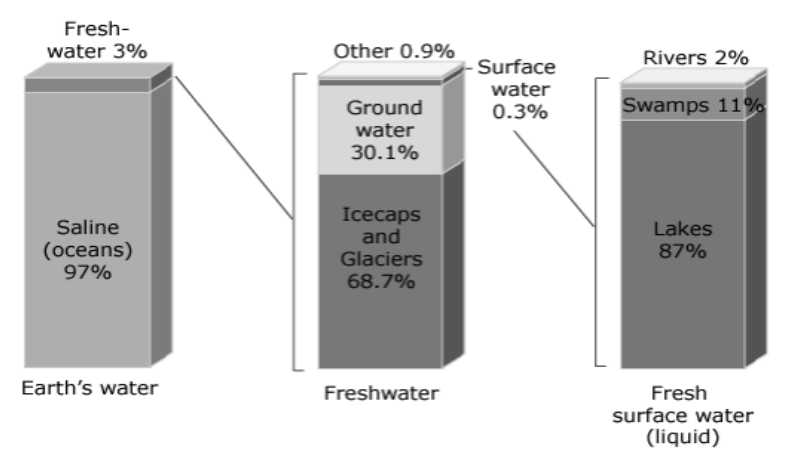

Figure (1): Distribution of Earth's Water after USGS

Currently population is using 54 per cent of available freshwater. According to forecast this rate will be 70 per cent by 2025 (Fig.2).

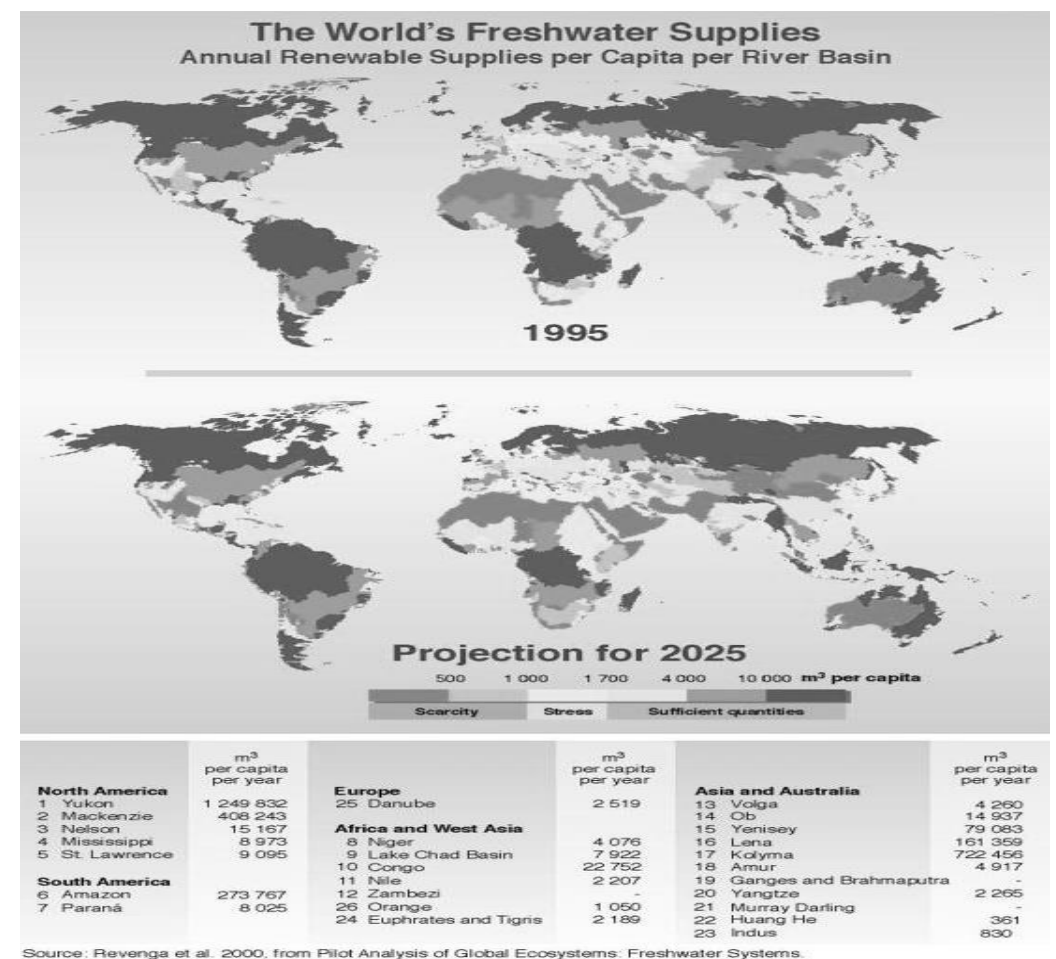

Figure (2): The World's renewable freshwater supplies and forecast (2025) after USGS

Several regions of the world are threatened by lack of freshwater that can cause different type of conflicts (for example stress between industrial factories in a country or war between foreign countries).

Egyptian J. of Phycol. Vol. 11, $2010 \quad$ - 122 - 
In Africa and Asia 5-8 million people die per year and 250 million people suffer from illnesses caused by polluted and infected water. All over the world especially in developing countries water pollution, destroying nature and overconsumption cause enormous problem (Somlyódi, 2003).

In case of water resources the most significant consumers are industry and agriculture and the smallest are households. It has frequently happened that farmers accustomed to traditional agricultural methods over-irrigate the soil causing salinization and lack of soil productivity.

Further challenges are how to identify new persistent and toxic compound like pesticide, steroid and hormone imbalance.

Purpose of all countries is to ensure long-term water supply. Due to climate changes the problems in connection with water are seriously expanding.

\subsection{Mechanism of Climate change}

Without greenhouse effect that is a natural process the global average temperature of Earth would be -18 degree. Currently the average temperature on Earth is +15 degree.

Due to human activities additional greenhouse gases have been emitted in the atmosphere like $\mathrm{CO}_{2}, \mathrm{CH}_{4}, \mathrm{NO}_{\mathrm{X}}$ that enhance the natural green house effect. This phenomenon is called broaden green house effect (Kocsis-Kupper, 2009).

1.2 Water changes in connection with climate changes (Figure 3)

The present climate of Earth is warming and its impacts on water have been observed.

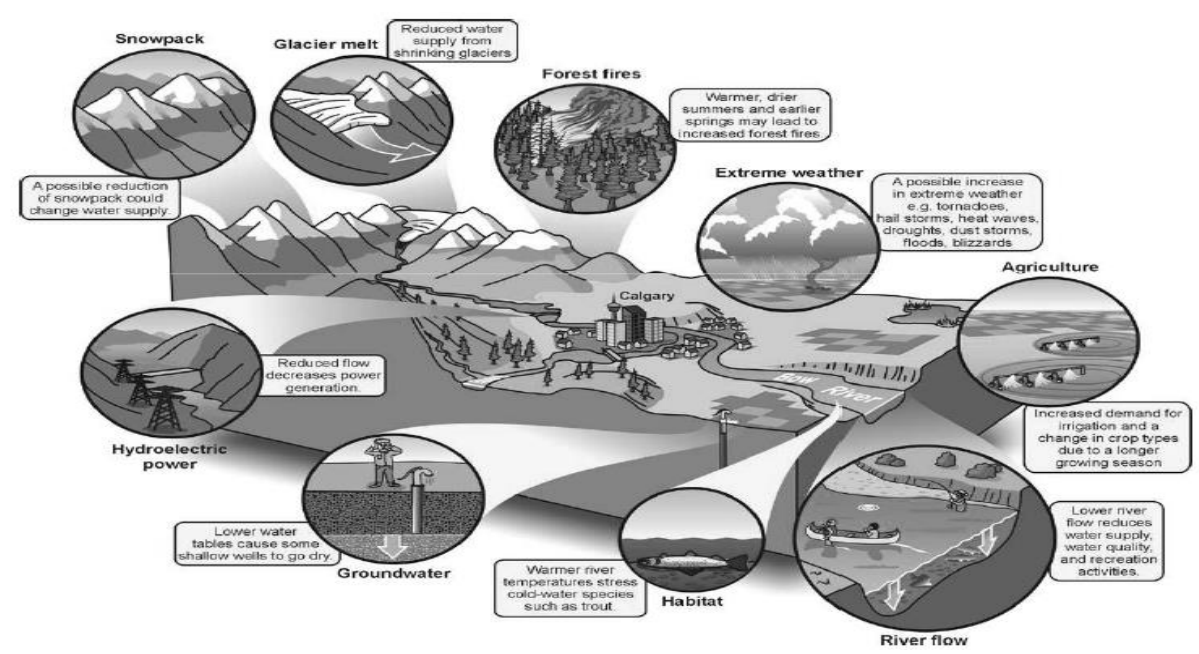

Figure (3): Water changes in connection with climate changes after Kocsis-Kupper, 2009

Egyptian J. of Phycol. Vol. 11, 2010

- 123 - 
- Disappearance of polar snow pack. Territory of polar snow pack of North Pole has been reduced. Some part of polar ice cap of Antarctic has become unstable.

- Melting of glacier: 75 per cent of glaciers in Alp will be likely to be disappeared by 2050 . The Fig. 4 presents melting process of Chachaltaya glacier (1940-2005).

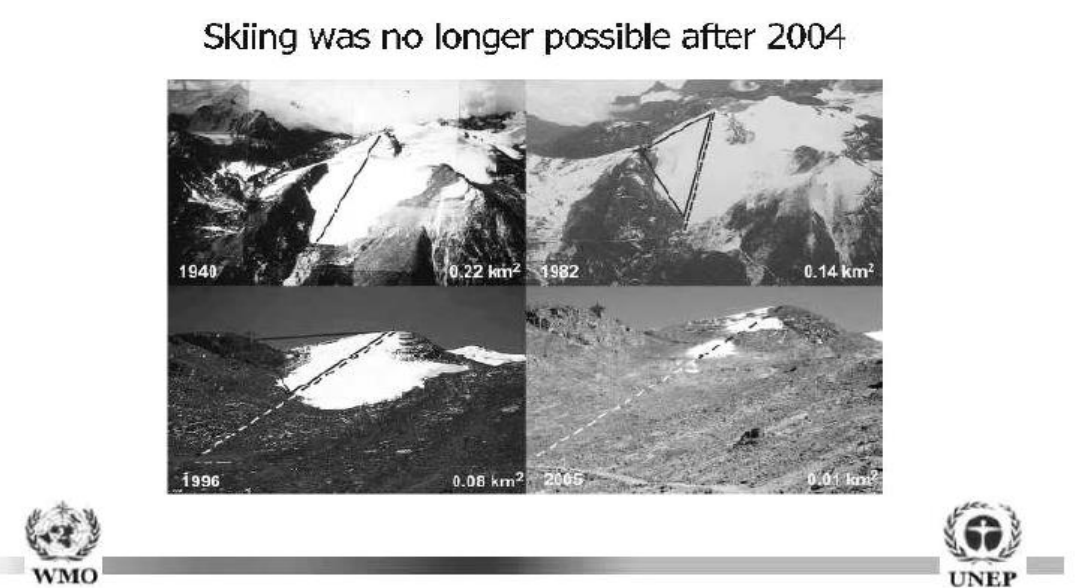

Figure (4): Melting process of Chacaltaya glacier (ski-lift, Bolivia) after KocsisKupper, 2009

- Increasing sea level: During the last century the sea level was increased 12-22 $\mathrm{cm}$. According to forecast this process will be continuing rapidly. As oceans and seas absorb significant level of carbon dioxide they are considered hyper sensitive by climate changes. The carbon dioxide is diluted more difficult in warmer water and this process causes acidity of oceans. Warm and acidity have sensitive touch to sea animals that are on the verge of extinction.

- Extreme weather: In the past decades numerous (three times more than 1960) disasters happened due to extreme weather including heat-wave, floods, drought and forest fire. These disasters cause appreciable human and economic damages.

- Endangered nature: Important part of flora and fauna will not be able to cope with increased temperature and shifted natural habitat.

\subsection{Impact of climate changes in Europe}

Gentle warming would have positive effect on agriculture in north Europe but additional temperature increasing would have negative effect on the volume. If the increasing level of temperature caused by climate changes has exceeded with 2

Egyptian J. of Phycol. Vol. 11, $2010 \quad$ - 124 - 
degree than agricultural volume will be decreased (Faragó, 2007). In south Europe the high temperature causes lack of water and less agricultural production. In 2003 during the heat-wave the volume of agriculture in the south European countries decreased with 30 per cent.

1.4 Impact of expected climate changes in Hungary

According to tendencies climate of Hungary turn into Mediterranean it means that summer weather it become hot and dry, winters turn into rainy and mild. Storms become heavier and appear more frequently in Hungary (National Climate Changes Strategy, 2008-2025).

In conclusion the impacts of global climate changes are mostly negative. Climate changes cause terrestrial higher maximum temperature (more days with extremely high temperature) and minimum temperature is increasing causing less cold, frozen days and cold fronts.

Heavy raining is become typical. Expanding drought in summer and intensified tropical cyclone appear frequently.

\section{CASE STUDY}

1.1 Impacts of human activities to environment

Minamata-case is one of the most serious disasters of the industrial environmental pollution. Mercury is a kind of nerve poison and can be accumulated in fish and mussels and got into human body by having them that can cause blindness and heavy failure in human body (Rédey, Utasi, Domokos, 2007).

Arsenic concentration in groundwater is a global problem, in China, Thailand, Taiwan, Argentina, Chile, Mexico, USA and Hungary. The wells in these countries naturally contain arsenic and level of its concentration exceeds the limit prescribed by WHO $(0,01 \mathrm{mg} / \mathrm{l})$ [5]. Several projects deal with the technology how to remove arsenic from groundwater in Hungary.

The following examples are emphasized in case of over fishing (Fig.5):

- Herring fishing in North Sea

- Unawares fishing (for example fishing of 1t shrimp 3t additional fish is hunted)

- Whale hunting

1.2 Water pollution and water scarcity are the most critical issues

International conflicts are connected with catchment areas that are divided among many different countries. Half of the population live in these areas (Jordan, Ganges, Nil, Danube, Rhine). It is presented by Table (1). 95 per cent of supplies Egyptian J. of Phycol. Vol. 11, 2010 
of surface water in Hungary come from aboard and its negative effects are that polluted water is able to enter the territory of Hungary.

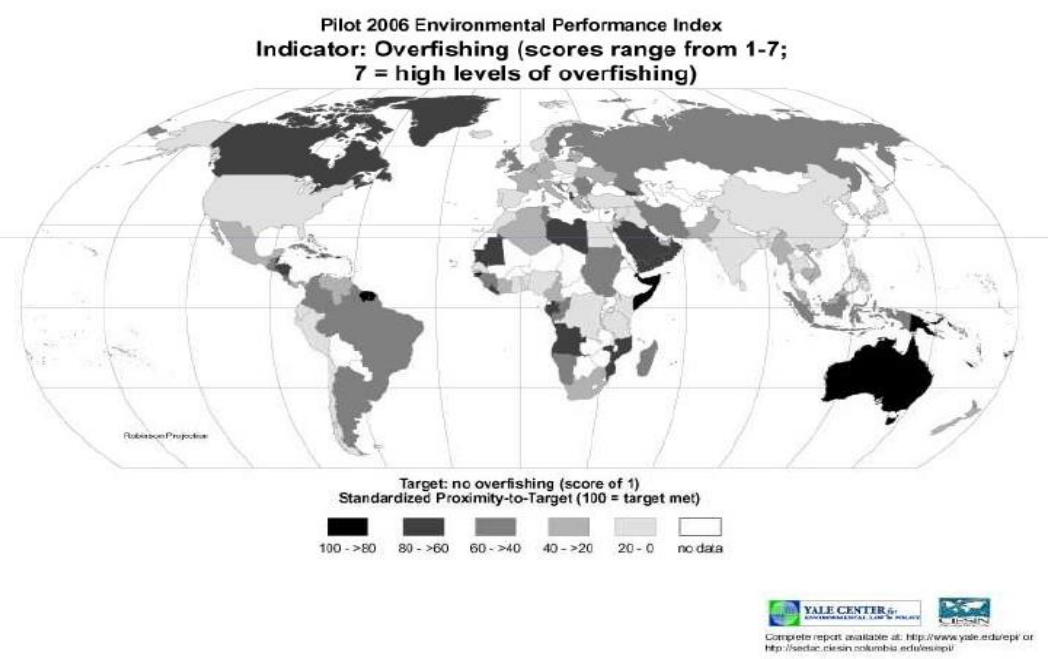

Figure (5): Distribution of over fishing on Earth after Kocsis-Kupper, 2009

Improvement of divided catchment areas is one of the most important future purposes in the 21st century. Europe is the number one that has been implemented Water Framework Directive (WFD) solving of above mentioned issue. The Water Framework Directive was created as long-term water policy of the European Union. Member States are required to achieve good ecological and chemical status in all bodies of surface water by 2015 (Directive 2000/60/EC). It is essential the cooperation of concerned countries to be able to perform Water Management Plans.

Table 1: Rate of surface water come from abroad after IPCC- Technical Paper VI., 2008

\begin{tabular}{|c|c|c|c|}
\hline Country & $\begin{array}{c}\text { Rate of surface water } \\
\text { come from aboard (\%) }\end{array}$ & Country & $\begin{array}{c}\text { Rate of surface water } \\
\text { come from aboard (\%) }\end{array}$ \\
\hline Turkmenistan & 98 & Netherlands & 89 \\
\hline Egypt & $\mathbf{9 7}$ & Gambia & 86 \\
\hline Hungarian & $\mathbf{9 5}$ & Cambodia & 82 \\
\hline Mauritania & 95 & Syria & 79 \\
\hline Botswana & 94 & Sudan & 77 \\
\hline Bulgaria & 91 & Niger & 68 \\
\hline Uzbekistan & 91 & Iraq & 42 \\
\hline
\end{tabular}

Hungary is part of the catchment area of Danube (Fig.6). Hungarian Water Management Plan was completed in 2009.

Egyptian J. of Phycol. Vol. 11, $2010 \quad$ - 126 - 
Both projects (WFD, Hungarian Water Management Plan) have the same purposes. These are the followings:

- The physical-chemical parameters of an aquatic body not only reflect the type and diversity of aquatic biota but also the water quality and pollution. Therefore regular monitoring is required (Chennakrishnan, Stephen, Manju and Raveen, 2008).

- Sustainable water consumption

- decreasing of pollution in surface water and groundwater

- Moderating the effects of droughts and floods.

- Sociality has the possibility to take part in decision process

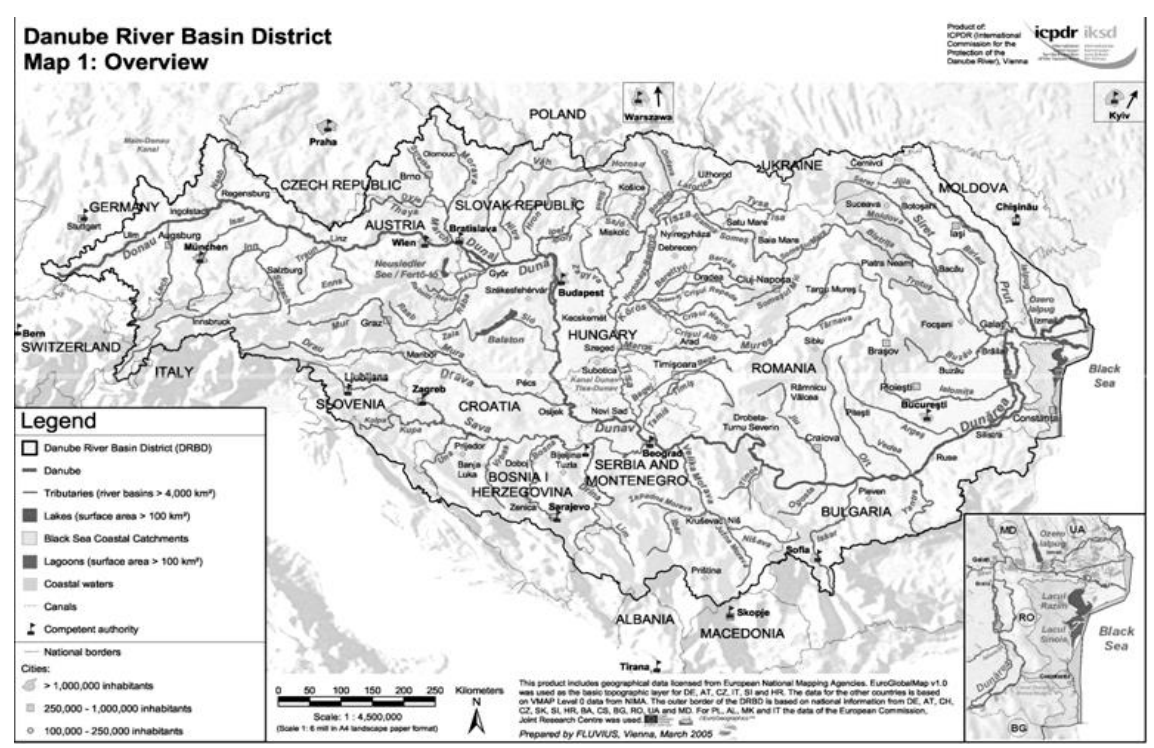

Figure (6): Danube's Basin District after Water Management Plan, 2009

Water resources of Hungary is characterised by its geological position and basin character. Water quality and quantity of Hungary are depends on climate changes.

In case of water quantity drought, floods and inland inundation are critical phenomena. In point of water quality the self cleaning ability of water can decrease. So degradation of pollutants will be more slowly that has also negative effect on water quality. Water quality depends on heavy raining too so sewage system become overloaded that cause overflowing, pollution and accident (National Climate Changes Strategy, 2008-2025). 
The most extreme drought period occurred in 2003 and 2007. Decrease of territory of Balaton (the largest lake in Middle Europe, $596 \mathrm{~km}^{2}$, average width is $5-6 \mathrm{~km}$, average length is $77 \mathrm{~km}$ ) was essential (Fig.7). In 2003 the water level of Balaton was critically under the accepted level. Due to drought and high summer temperature territory of several small lakes can decrease; numerous of them are arid forever (Clement, 2009).

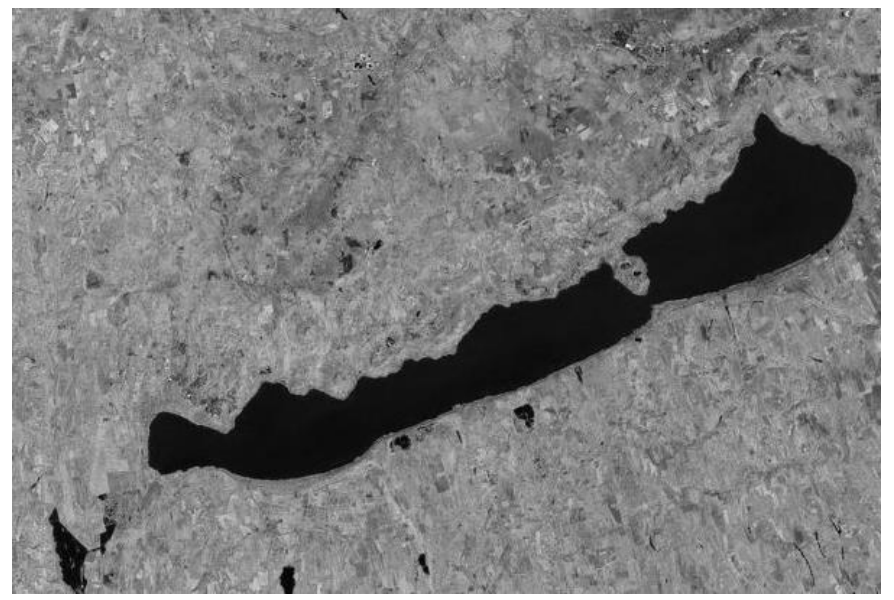

Figure (7): The largest lake in Middle Europe is Balaton after Clement, 2009

Water shortage and aridity is not only water supply problem but they have direct impacts on human, nature and economic sectors like agriculture, tourism, industry and energy and transportation (National Climate Changes Strategy, 2008-2025).

It is essential to install sewage technologies that can maintain the natural self cleaning ability of streams. It is also important taking into consideration that biological cleaning methods are highly depends on temperature. Temperature growth is able to modify the cleaning efficiency.

Supply of ground water (karstic) is essential as it is able to ensure 90 per cent of drinking water in Hungary as well. Groundwater is also extreme reactive to climate changes. Climate changes have an effect to border condition of water supply and tapping. Drastic decrease of subsurface water supply is caused by increasing evaporation.

\section{Conclusion}

Climate change involves not only warming but length and frequency of drought periods that urges increased protection of natural water.

Water scarcity in Hungary is also a real danger although Hungary is considered abundance of freshwater. In the future value of freshwater will be over estimated.

Egyptian J. of Phycol. Vol. 11, $2010 \quad$ - 128 - 
Flora and fauna have to adapt to the new circumstances it means that the most dangerous areas should be monitored and new directives are necessary to be installed to be able to decrease future risks.

\section{References}

Chennakrishnan, C.; Stephen, A.; Manju, T. and Raveen, R. (2008). Water quality status of three vulnerable freshwater lakes of suburban Chenooi, India

Clement A. (2009). Surface water and climate change, Budapest University of Technology and Economics

Directive 2000/60/EC of the European Parliament and of the Council

Faragó, G. (2007). Climate Changes 2007 (IPCC-IV. Report)

IPCC- Technical Paper VI. (2008). Climate Change and Water, Intergovernmental panel on climate change, ISBN: 978-92-9169-123-4

Kocsis-Kupper, Zs. (2009). International environmental legal

National Climate Changes Strategy (2008-2025). Hungary

Rédey, Á.; Utasi, A.; Domokos, E. (2007). State of Earth, Published by the University of Pannonia

Somlyódi, L. (2003). From the stream to the ocean- Fresh water future challenge

USGS - Science for a changing world

World Water Day (2007). Coping with water scarcity, UN Water

Water Management Plan (2009). Hungarian Water Management Plan.

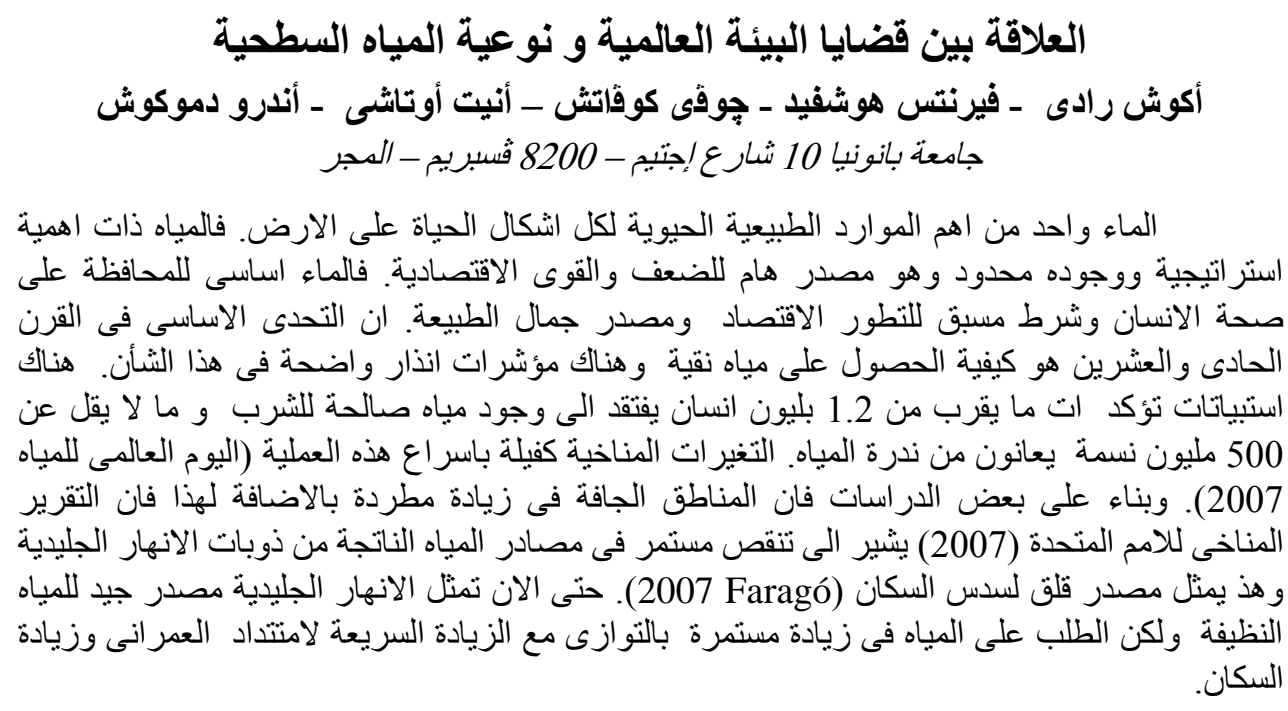

